\title{
Dietary Nucleotides Influence Lipoprotein Metabolism in Newborn Infants
}

\author{
A. SẢNCHEZ-POZO, J. MORILlAS, L. MOLTÓ, R. ROBLES, AND A. GIL \\ Department of Biochemistry and Molecular Biology, University of Granada, [A. S.-P., J. M., A. G.] and \\ Department of Paediatrics, Materno-Infantil Hospital [L. M., R. R.], Granada, Spain
}

\begin{abstract}
Nucleotide supplementation of adapted-milk formulas may be of interest for infant nutrition because nucleotides are involved in the synthesis of proteins and other macromolecules such as phospholipids, and thereby facilitate lipoprotein synthesis. To determine whether dietary nucleotides influence plasma lipoproteins in newborns, we have studied the plasma-lipoprotein concentrations and the composition of the major lipoprotein fractions during the first week of life in two groups of preterm infants fed formulas differing only in their nucleotide content. For comparison, two groups of term infants were studied under the same conditions. Lipoproteins were isolated by density ultracentrifugation, and the lipid and protein content were determined by standard methods; apolipoprotein A-I was determined immunologically. Nucleotide supplementation of formula in preterm infants increased all plasma lipoprotein concentrations. In addition, an increase in the plasma esterification rate was observed. However, total cholesterol concentrations were unchanged. The changes in lipoproteins concentrations were due mainly to an increase in apolipoprotein content. Nucleotides added to formulas affected term-infants' lipoproteins significantly less than to perterm infants. These findings suggest that dietary nucleotides may enhance the synthesis of lipoproteins during the early neonatal period, especially in preterm infants. (Pediatr Res 35: 112-116, 1994)
\end{abstract}

\section{Abbreviations}

LCAT, lecithin/cholesterol-acyl transferase

CMP, cytidine monophosphate

UMP, uridine monophosphate

IMP, inosine monophosphate

PTI-NFF, preterm infants fed nucleotide-free formula

PTI-NSF, preterm infants fed nucleotide-supplemented formula

TI-NFF, term infants fed nucleotide-free formula

TI-NSF, term infants fed nucleotide-supplemented formula

Nucleotides are present in most food products as nucleic acids from which nucleotides are released after digestion (1). Nucleic acids as well as free nucleotides are found in human milk in significant amounts $(2,3)$, and the nutritional role of these components is currently under study. Dietary nucleotides seem to influence several aspects of neonatal development (4-9), but little is known about the influence of nucleotides in lipoprotein

Received September 15, 1992; accepted August 31, 1993.

Correspondence: Prof. Dr. Antonio Sánchez-Pozo, Department of Biochemistry and Molecular Biology, Faculty of Pharmacy. University of Granada, Campus Cartuja s/n. 18071-Granada, Spain.

Supported in part by a grant from Uniasa, Granada, Spain. metabolism, which is an important aspect in neonatal development.

Early studies using rats suggested that nucleotides affect liver lipoprotein secretion by changes in apo synthesis (10-12), and more recently it has been reported that nucleotides appear to be modulators of intestinal growth and development by stimulating protein synthesis $(13,14)$. According to these studies a balance of dietary nucleotides might be necessary to maintain normal lipoprotein secretion.

In previous studies we reported that nucleotide supplementation increased plasma lipoproteins in newborns. In newborn rats nucleotide supplementation increased plasma VLDL and HDL concentrations (15). In term newborn infants nucleotide supplementation increased HDL-cholesterol (16). In the present study, we investigate how adding nucleotides to adapted milk formulas affects plasma lipoprotein concentrations and composition during the first week of life in newborn preterm infants. Term infants were studied for comparison.

\section{SUBJECTS AND METHODS}

Four groups of 10 infants each were studied: 1) preterm infants fed a nucleotide-free formula (PTI-NFF); $34.9 \pm 0.3 \mathrm{wk}$ gestational age and $2.21 \pm 0.17 \mathrm{~kg}$ in birth weight; 2) preterm infants fed the same formula supplemented with nucleotides (PTI-NSF); $34.4 \pm 0.7$ wk gestational age and $2.08 \pm 0.26 \mathrm{~kg}$ in birth weight; 3) term infants fed a nucleotide-free formula (TI-NFF); $39.4 \pm$ $1.1 \mathrm{wk}$ gestational age and $3.58 \pm 0.50 \mathrm{~kg}$ in birth weight; and 4) term infants fed the same formula supplemented with nucleotides (TI-NSF); $39.1 \pm 0.9$ wk gestational age and $3.19 \pm 0.26$ $\mathrm{kg}$ in birth weight.

Gestational age, expressed as weeks from the last menstrual period, was established on the basis of maternal history and confirmed by the Dubowitz examination of the newborn (17). The mothers had suffered no complications of pregnancy or parturition. Only disease-free infants were included in the study.

All infants were fed exclusively on formulas following the European Society of Pediatric Gastroenterology and Nutrition recommendations $(18,19)$. The formula used for preterm infants contained $2.9 \mathrm{~g}$ of protein, $5.4 \mathrm{~g}$ of lipids, $9.9 \mathrm{~g}$ of carbohydrates, $0.6 \mathrm{~g}$ of minerals, and various vitamins per $100 \mathrm{kcal}$ of formula. The formula used for term infants contained $2.4 \mathrm{~g}$ of proteins, $5.1 \mathrm{~g}$ of lipids, $11.1 \mathrm{~g}$ of carbohydrates, $0.5 \mathrm{~g}$ of minerals, and various vitamins per $100 \mathrm{kcal}$ of formula. The nucleotide content in the formulas, when added $(\mathrm{mg} / 100 \mathrm{kcal})$, was: $0.66 \mathrm{UMP}$, 0.28 GMP, 0.25 AMP, 0.21 CMP, and 0.09 IMP.

The procedure was approved by the Committee for Research on Human Subjects of Granada Materno-Infantil Hospital and informed consent was obtained from the parents.

Blood samples were taken on d 0 (umbilical cord) and on d 3 and 7 after birth, immediately before feeding. Venous blood, collected in tubes containing EDTA as anticoagulant $(1 \mathrm{mg} /$ $\mathrm{mL}$ ), was centrifuged, and the resulting plasma was stored frozen at $-20^{\circ} \mathrm{C}$ until the assay. 
Lipoproteins were isolated by sequential microultracentrifugation (20), using a Beckman TL-100 ultracentrifuge. Plasma $(400 \mu \mathrm{L})$ was transferred to a centrifuge tube and gently mixed with $300 \mu \mathrm{L}$ of a cesium-chloride solution (density $=1.019 \mathrm{~g} /$ $\mathrm{mL}$ ). Samples were centrifuged for $5 \mathrm{~h}$ at $50000 \mathrm{rpm}$. The top fraction $(300 \mu \mathrm{L})$ containing VLDL was collected. The subnatant was then mixed with $400 \mu \mathrm{L}$ of cesium-chloride solution (density $=1.102 \mathrm{~g} / \mathrm{mL}$ ) and centrifuged for $18 \mathrm{~h}$ at $50000 \mathrm{rpm}$. The top fraction $(400 \mu \mathrm{L})$ containing LDL was collected. Finally, the subnatant was mixed with $440 \mu \mathrm{L}$ of a cesium-chloride solution (density $=1.310 \mathrm{~g} / \mathrm{mL}$ ) and centrifuged as before. The top fraction $(200 \mu \mathrm{L})$ containing $\mathrm{HDL}$ was collected. All centrifugations were made at $4^{\circ} \mathrm{C}$, and all solutions contained $0.1 \%$ EDTA and $0.02 \%$ sodium azide to minimize degradation. Isolated lipoprotein fractions were tested for cross-contamination by polyacrylamide-gel-electrophoresis using the Lipophor kit (Quantimetrix, Hawthorne, CA).

Glucose, urea, and uric acid were analyzed with commercial enzymatic assay kits (Biotrol, France). Plasma proteins were determined by the biuret method, using a commercial kit (Cromatest, Spain). Total cholesterol and free cholesterol were determined enzymatically using the Biotrol assay kits; the difference between these values was considered to be the esterified cholesterol concentration. Triglycerides were assayed using the Boehringer Mannheim fully enzymatic test combination kit (Germany). Phospholipids were estimated by the choline content, according to Takayama $e t$ al. (21) using a kit supplied by Boehringer Mannheim. Total apo was determined by Bradford's method (22), using bovine albumin as a standard. Apo A-I concentrations were determined with specific antibodies using the Sebia Hydragel electroimmune-diffusion kit (France).

Results are expressed as mean $\pm \mathrm{SD}$. Comparisons between term and preterm infants and between milk formulas were made using analysis of the variance and post hoc tests using the BMDP statistics software package (University of California, Los Angeles, CA).

\section{RESULTS}

Body weight and the intake of energy, protein, and nucleotides were monitored throughout the experimental period. No significant differences were observed between groups. The weights on d 7 were $3.37 \pm 0.50 \mathrm{~kg}$ in TI-NFF and $3.18 \pm 0.27 \mathrm{~kg}$ in TINSF, and $2.05 \pm 0.25 \mathrm{~kg}$ in PTI-NFF and $2.19 \pm 0.19 \mathrm{~kg}$ in PTINSF. The energy intake $(\mathrm{kcal} / \mathrm{kg} / \mathrm{d})$ increased over the study period from $32 \pm 6$ to $89 \pm 11$ in TI-NFF, from $37 \pm 7$ to $86 \pm$ 12 in TI-NSF, and from $25 \pm 8$ to $87 \pm 11$ in PTI-NFF, and from $31 \pm 3$ to $95 \pm 10$ in PTI-NSF. The intake of protein $(\mathrm{g} /$ $\mathrm{kg} / \mathrm{d}$ ) increased from $0.92 \pm 0.17$ to $2.58 \pm 0.31$ in TI-NFF, from $1.07 \pm 0.20$ to $2.49 \pm 0.34$ in TI-NSF, from $0.72 \pm 0.23$ to $2.52 \pm 0.31$ in PTI-NFF, and from $0.89 \pm 0.08$ to $2.75 \pm 0.29$ in PTI-NSF. The intake of nucleotides $(\mathrm{mg} / \mathrm{kg} / \mathrm{d})$ increased from $0.55 \pm 0.1$ to $1.28 \pm 0.17$ in TI-NSF, and from $0.46 \pm 0.2$ to $1.41 \pm 0.14$ in PTI-NSF. Routine analyses of such parameters as blood glucose, plasma proteins, and urea gave similar results in all groups. Blood glucose increased after birth from $2.8 \pm 0.1$ (mmol/L) to $4.4 \pm 0.1$ in TI-NFF, from $2.7 \pm 0.2$ to $4.6 \pm 0.3$ in TI-NSF, from $2.4 \pm 0.1$ to $4.0 \pm 0.1$ in PTI-NFF, and from $2.3 \pm 0.1$ to $4.1 \pm 0.3$ in PTI-NSF. Plasma protein concentrations did not change significantly: on $\mathrm{d} 0$ were $(\mathrm{g} / \mathrm{L}) 61 \pm 12$ in TINFF and $63 \pm 9$ in TI-NSF, $58 \pm 5$ in PTI-NFF, and $59 \pm 4$. On $d 7$, they were $61 \pm 7$ in TI-NFF, $67 \pm 4$ in TI-NSF, $60 \pm 4$ in PTI-NFF, and $64 \pm 3$ in PTI-NSF. Urea concentrations remained almost constant: on $\mathrm{d} 0$ (mmol/L) $4.4 \pm 0.8$ in TINFF, $4.5 \pm 0.9$ in TI-NSF, $5.7 \pm 1.9$ in PTI-NFF, and $5.6 \pm 1.2$. On $\mathrm{d} 7$, they were $4.2 \pm 1.4$ in TI-NFF, $4.4 \pm 0.8$ in TI-NSF, $3.7 \pm 1.1$ in PTI-NFF, and $3.8 \pm 0.9$ in PTI-NSF. Plasma uric acid were not significantly increased by the nucleotide treatment; on $\mathrm{d} 7$ the concentrations were $(\mathrm{mmol} / \mathrm{L}) 154 \pm 29$ in TI-NSF,
$154 \pm 23$ in PTI-NSF, $136 \pm 11$ in TI-NFF, and $136 \pm 5$ in PTINFF.

Plasma total-cholesterol concentrations and cholesterol-esters, as a fraction of total cholesterol, in the different groups are shown in Table 1. Plasma total-cholesterol concentrations increased after birth, and were similar in the groups receiving the supplemented formula than in the groups receiving the unsupplemented formula. However, the cholesterol-esters proportion was higher in PTI-NSF (a proportion similar to that of term infants with or without nucleotides), but remained unchanged after birth in PTI-NFF.

For the different groups, the total amount of plasma lipoproteins was calculated as the sum of the protein and lipid content determined in the isolated lipoproteins (Table 1). The amounts of all lipoprotein fractions in PTI-NSF were higher than in PTINFF. The effect of nucleotides in the feeding was consistent for VLDL and HDL $(p<0.01)$, but differed over time for LDL being significant $(p<0.01)$ on $\mathrm{d} 3$ but not on $\mathrm{d} 7$. In term infants, the only significant change was a nucleotide-related increase in VLDL on $\mathrm{d} 7$.

At birth, the lipoprotein composition was similar in all groups (Table 2), however, we found differences between supplemented and unsupplemented groups on d 3 (Table 3) and 7 (Table 4), especially in preterm infants.

Protein content in lipoproteins of preterm infants receiving nucleotides was significantly higher than in those not receiving nucleotides (Tables 3 and 4). The major and most consistent differences observed were in HDL $(p<0.001)$, whereas the increase in the other lipoproteins fractions was significant on $d$ $3(p<0.001)$ but not on $\mathrm{d} 7$. At this age the difference in VLDL was significant $(p<0.05)$, whereas the difference in LDL was not. In term infants, the only significant change observed was in HDL on $\mathrm{d} 7(p<0.05)$. Further characterization of apo in HDL revealed that the relative apo A-I content was similar in both groups of preterm infants. However, a higher value was found in term infants receiving nucleotides (Table 5).

In general, the lipid content in preterm infants receiving nucleotides was higher than in preterm infants not receiving nucleotides, the major changes being observed on d 3 (Table 3 ). The increase in cholesterol was greater than in triglycerides or phospholipids. In HDL the cholesterol content increased less than in the other lipoproteins. The major changes in term infants receiving nucleotides were observed on d 7 (Table 4). All lipid classes were higher in the VLDL from the infants receiving nucleotides.

The lipid-to-protein ratio in the lipoproteins of preterm and term infants receiving nucleotides was in general lower than in infants not receiving the nucleotides, although the ratio fluctuated with time. On $\mathrm{d} 3$ in preterm infants, this ratio decreased from 18 to 14 in VLDL, from 1.7 to 1.2 in LDL, and from 1.8 to 1.1 in HDL. No changes were observed on $d 7$ except for a decrease in HDL from 1.8 to 1.3 . In term infants on $\mathrm{d} 7$, the ratio decreased from 3.1 to 2.0 in $\mathrm{LDL}$ and from 1.8 to 1.4 in HDL. By contrast VLDL increased from 13 to 21 . No changes were observed on $\mathrm{d} 3$.

\section{DISCUSSION}

The data presented in this communication indicate that nucleotides added to adapted-milk formulas increased plasma lipoprotein concentrations in newborn infants, mainly in preterm infants. These results confirm our previous reports in term newborn infants where we found an increase in plasma HDLcholesterol (16) and in rats fed nucleotide-supplemented diets where we found an increase in HDL (15). The explanation for the greater effect in preterm infants than in term infants remains unclear. Plasma lipoprotein changes early after birth are reportedly less pronounced in preterm than in term infants (23). This difference could be related to immaturity of the gut and/or liver functions in preterms. Our findings imply that nucleotides, in facilitating lipid transport may contribute to energy homeostasis 
Table 1. Plasma lipids and lipoproteins in newborn infants according to the postnatal age and the type of formula*

\begin{tabular}{|c|c|c|c|c|c|c|}
\hline Group & $\begin{array}{c}\text { Age } \\
\text { (days after birth) }\end{array}$ & $\begin{array}{c}\mathrm{TC} \\
(\mathrm{mmol} / \mathrm{L})\end{array}$ & $\mathrm{CE}$ & $\begin{array}{l}\text { VLDL } \\
(\mathrm{g} / \mathrm{L})\end{array}$ & $\begin{array}{l}\text { LDL } \\
(\mathrm{g} / \mathrm{L})\end{array}$ & $\begin{array}{l}\text { HDL } \\
(\mathrm{g} / \mathrm{L})\end{array}$ \\
\hline \multirow[t]{3}{*}{ TI-NFF } & 0 & $1.63(0.25)$ & $0.45(0.03)$ & $0.27(0.15)$ & $0.88(0.12)$ & $1.45(0.15)$ \\
\hline & 3 & $2.45(0.18)$ & $0.55(0.03)$ & $0.60(0.12)$ & $1.11(0.34)$ & $1.62(0.25)$ \\
\hline & 7 & $2.72(0.41)$ & $0.62(0.09)$ & $0.65(0.09)$ & $1.03(0.18)$ & $1.86(0.37)$ \\
\hline \multirow[t]{3}{*}{ TI-NSF } & 0 & $1.61(0.22)$ & $0.47(0.03)$ & $0.27(0.10)$ & $0.81(0.11)$ & $1.49(0.15)$ \\
\hline & 3 & $2.42(0.12)$ & $0.61(0.06)$ & $0.58(0.06)$ & $1.03(0.18)$ & $1.50(0.18)$ \\
\hline & 7 & $2.73(0.31)$ & $0.64(0.09)$ & $0.99(0.28) \ddagger$ & $1.20(0.34)$ & $1.99(0.28)$ \\
\hline \multirow[t]{3}{*}{ PTI-NFF } & 0 & $1.97(0.25)$ & $0.49(0.18)$ & $0.34(0.06)$ & $0.90(0.08)$ & $1.38(0.18)$ \\
\hline & 3 & $2.66(0.12)$ & $0.50(0.03)$ & $0.53(0.06)$ & $1.09(0.06)$ & $1.45(0.15)$ \\
\hline & 7 & $2.67(0.18)$ & $0.50(0.06)$ & $0.62(0.15)$ & $1.39(0.15)$ & $1.56(0.15)$ \\
\hline \multirow[t]{3}{*}{ PTI-NSF } & 0 & $1.91(0.20)$ & $0.48(0.07)$ & $0.36(0.05)$ & $0.92(0.09)$ & $1.48(0.13)$ \\
\hline & 3 & $2.79(0.09) \dagger$ & $0.62(0.09) \ddagger$ & $0.74(0.18) \ddagger$ & $1.60(0.18) \S$ & $1.98(0.47) \ddagger$ \\
\hline & 7 & $2.90(0.15) \dagger$ & $0.65(0.06) \S$ & $0.81(0.09) \ddagger$ & $1.53(0.16)$ & $2.12(0.22) \S$ \\
\hline
\end{tabular}

* Values are mean with SD in parentheses. Abbreviations are: TC, total cholesterol; CE, cholesterol esters (as a fraction of total cholesterol); VLDL, LDL, HDL concentrations as the sum of their lipids and protein concentrations.

$\dagger$ Significant differences between NFF and NSF groups, $p<0.05$.

$\ddagger$ Significant differences between NFF and NSF groups, $p<0.01$.

$\S$ Significant differences between NFF and NSF groups, $p<0.001$.

Table 2. Lipoprotein composition at birth in the different groups of infants*

\begin{tabular}{cllccc}
\hline Group & Fraction & $\begin{array}{c}\text { Cholesterol } \\
(\mathrm{mmol} / \mathrm{L})\end{array}$ & $\begin{array}{c}\text { Triglycerides } \\
(\mathrm{mmol} / \mathrm{L})\end{array}$ & $\begin{array}{c}\text { Phospholipids } \\
(\mathrm{mmol} / \mathrm{L})\end{array}$ & $\begin{array}{c}\text { Apo } \\
(\mathrm{g} / \mathrm{L})\end{array}$ \\
\hline TI-NFF & VLDL & $0.15(0.06)$ & $0.13(0.06)$ & $0.06(0.02)$ & $0.02(0.00)$ \\
& LDL & $0.34(0.09)$ & $0.18(0.12)$ & $0.39(0.17)$ & $0.29(0.12)$ \\
TI-NSF & HDL & $0.65(0.10)$ & $0.06(0.02)$ & $0.76(0.08)$ & $0.53(0.15)$ \\
& VLDL & $0.18(0.09)$ & $0.12(0.09)$ & $0.06(0.03)$ & $0.02(0.01)$ \\
PTI-NFF & LDL & $0.35(0.12)$ & $0.16(0.07)$ & $0.47(0.09)$ & $0.33(0.13)$ \\
& HDL & $0.59(0.18)$ & $0.07(0.02)$ & $0.77(0.15)$ & $0.54(0.12)$ \\
& VLDL & $0.31(0.10)$ & $0.16(0.06)$ & $0.05(0.02)$ & $0.03(0.01)$ \\
PTI-NSF & LDL & $0.31(0.12)$ & $0.18(0.13)$ & $0.35(0.13)$ & $0.34(0.15)$ \\
& HDL & $0.60(0.17)$ & $0.04(0.02)$ & $0.69(0.08)$ & $0.56(0.12)$ \\
& VLDL & $0.36(0.13)$ & $0.16(0.05)$ & $0.07(0.02)$ & $0.03(0.01)$ \\
& LDL & $0.32(0.15)$ & $0.18(0.12)$ & $0.38(0.17)$ & $0.36(0.14)$ \\
\hline
\end{tabular}

* Values are mean with SD in parentheses.

Table 3. Lipoprotein composition in 3-d-old newborn infants as a function of the type of formula*

\begin{tabular}{cllccc}
\hline Group & Fraction & $\begin{array}{c}\text { Cholesterol } \\
(\mathrm{mmol} / \mathrm{L})\end{array}$ & $\begin{array}{c}\text { Triglycerides } \\
(\mathrm{mmol} / \mathrm{L})\end{array}$ & $\begin{array}{c}\text { Phospholipids } \\
(\mathrm{mmol} / \mathrm{L})\end{array}$ \\
\hline TI-NFF & VLDL & $0.50(0.28)$ & $0.30(0.12)$ & $0.13(0.06)$ & $0.04(0.02)$ \\
& LDL & $0.61(0.18)$ & $0.17(0.12)$ & $0.50(0.18)$ & $0.32(0.12)$ \\
& HDL & $0.72(0.25)$ & $0.10(0.06)$ & $0.81(0.12)$ & $0.61(0.13)$ \\
TI-NSF & VLDL & $0.53(0.15)$ & $0.27(0.09)$ & $0.12(0.03)$ & $0.04(0.01)$ \\
& LDL & $0.55(0.12)$ & $0.16(0.09)$ & $0.47(0.09)$ & $0.30(0.15)$ \\
& HDL & $0.59(0.18)$ & $0.07(0.03)$ & $0.78(0.15)$ & $0.58(0.18)$ \\
PTI-NFF & VLDL & $0.53(0.18)$ & $0.36(0.25)$ & $0.08(0.05)$ & $0.03(0.01)$ \\
& LDL & $0.48(0.12)$ & $0.14(0.06)$ & $0.47(0.12)$ & $0.40(0.06)$ \\
& HDL & $0.80(0.47)$ & $0.10(0.06)$ & $0.76(0.12)$ & $0.55(0.21)$ \\
& VLDL & $0.86(0.34) \dagger$ & $0.46(0.15)$ & $0.11(0.08)$ & $0.06(0.01) \dagger$ \\
& LDL & $0.92(0.15) \ddagger$ & $0.18(0.12)$ & $0.58(0.18)$ & $0.70(0.15) \ddagger$ \\
& HDL & $0.65(0.37)$ & $0.16(0.06) \dagger$ & $1.00(0.12) \ddagger$ & $1.03(0.25) \ddagger$ \\
\hline
\end{tabular}

* Values are mean with SD in parentheses.

† Significant differences between NFF and NSF groups, $p<0.05$.

‡ Significant differences between NFF and NSF groups, $p<0.001$.

and growth in the newborn, especially in the preterm infant, who need to adapt more rapidly after birth.

The mechanism by which dietary nucleotides influence lipoprotein metabolism cannot be fully ascertained from these data. However, our results indicate that nucleotides facilitate apo synthesis. In addition, nucleotides may facilitate the synthesis of phospholipids by increasing the availability of cytidine diphosphate-derivatives, as we have reported in newborn rats (24). The combined effects on both apo and phospholipids would enhance lipoprotein synthesis.
The liver and the intestine are the principal organs involved in lipoprotein synthesis, and we think that the main effect of nucleotides takes place in the intestine. There is growing evidence that dietary nucleotides promote intestinal maturity. These nucleotides are actively taken up by the intestine (25), which in fact has a limited capacity for de novo purine synthesis (26). Moreover, the administration of nucleotides increases intestinal oligosaccharidase activities (13) indicating that nucleotides can contribute to intestinal maturation. Recently, Nuñez et al. (14) have reported that in rats at weaning the intestinal DNA, protein, 
Table 4. Lipoprotein composition in 7-d-old newborn infants as a function of type of formula*

\begin{tabular}{cllccc}
\hline Group & Fraction & $\begin{array}{c}\text { Cholesterol } \\
(\mathrm{mmol} / \mathrm{L})\end{array}$ & $\begin{array}{c}\text { Triglycerides } \\
(\mathrm{mmol} / \mathrm{L})\end{array}$ & $\begin{array}{c}\text { Phospholipids } \\
(\mathrm{mmol} / \mathrm{L})\end{array}$ & $\begin{array}{c}\text { Apo } \\
(\mathrm{g} / \mathrm{L})\end{array}$ \\
\hline TI-NFF & VLDL & $0.31(0.18)$ & $0.33(0.09)$ & $0.23(0.10)$ & $0.05(0.01)$ \\
& LDL & $0.50(0.12)$ & $0.10(0.09)$ & $0.62(0.06)$ & $0.25(0.42)$ \\
& HDL & $0.99(0.34)$ & $0.13(0.06)$ & $0.92(0.09)$ & $0.68(0.25)$ \\
TI-NSF & VLDL & $0.82(0.15) \ddagger$ & $0.42(0.06) \dagger$ & $0.31(0.05) \dagger$ & $0.05(0.02)$ \\
& LDL & $0.57(0.03)$ & $0.14(0.06)$ & $0.57(0.06)$ & $0.40(0.22)$ \\
& HDL & $0.75(0.28)$ & $0.15(0.08)$ & $1.07(0.12) \dagger$ & $0.86(0.18) \dagger$ \\
& VLDL & $0.51(0.18)$ & $0.35(0.12)$ & $0.08(0.06)$ & $0.03(0.02)$ \\
& LDL & $0.50(0.22)$ & $0.07(0.03)$ & $0.74(0.18)$ & $0.55(0.31)$ \\
& HDL & $0.70(0.22)$ & $0.21(0.12)$ & $0.78(0.15)$ & $0.58(0.18)$ \\
& VLDL & $0.73(0.15) \dagger$ & $0.43(0.12)$ & $0.12(0.09)$ & $0.06(0.01) \dagger$ \\
& LDL & $0.86(0.18) \ddagger$ & $0.12(0.06) \dagger$ & $0.59(0.06) \dagger$ & $0.62(0.15)$ \\
& HDL & $0.88(0.09) \dagger$ & $0.20(0.05)$ & $0.87(0.06)$ & $0.91(0.15) \ddagger$ \\
\hline
\end{tabular}

* Values are mean with SD in parentheses.

† Significant differences between NFF and NSF, $p<0.05$.

¥ Significant differences between NFF and NSF, $p<0.001$.

Table 5. Apo A-I in HDL in newborn infants according to the postnatal age and the type of formula*

\begin{tabular}{cccl}
\hline Group & $0 \mathrm{~d}$ & \multicolumn{1}{c}{$3 \mathrm{~d}$} & \multicolumn{1}{c}{$7 \mathrm{~d}$} \\
\hline TI-NFF & $0.57(0.03)$ & $0.49(0.06)$ & $0.53(0.12)$ \\
TI-NSF & $0.55(0.04)$ & $0.54(0.09)$ & $0.66(0.12) \dagger$ \\
PTI-NFF & $0.54(0.09)$ & $0.51(0.06)$ & $0.58(0.12)$ \\
PTI-NSF & $0.55(0.09)$ & $0.54(0.15)$ & $0.62(0.09)$ \\
\hline
\end{tabular}

* Values are mean expressed as milligrams of apo A-I per milligrams of total protein; SD in parentheses.

$\dagger p<0.05$ vs TI-NFF.

and oligosaccharide activities which were decreased by fasting, or by chronic diarrhea are restored more quickly when rats are fed a nucleotide-supplemented diet than when fed a nucleotidefree diet.

The effect of nucleotides in the intestine might be of great influence in lipoprotein metabolism during the first week of life. It has been suggested that normal gastrointestinal function might be a prerequisite for rapid postnatal lipoprotein metabolism (27). Intestinal synthesis of HDL is significant during the postnatal period (28). In addition, HDL and other lipoproteins and apo synthesized in the intestine during fat absorption may affect LCAT activity (27) and could explain the differences in the cholesterol esterification observed.

Another finding in this study may be related to lipid tolerance in preterm infants. A lower capacity for cholesterol esterification at birth and during the early postnatal age in preterm infants has been reported $(23,29-31)$. The preterm infants who received nucleotides showed a proportion of plasma cholesterol-esters close to that found in term infants, whereas this proportion remained low in the group fed the nucleotide-free formula. The amount of cholesterol-esters found in the group receiving nucleotides was similar to that found in term breast-fed infants at 1 wk of age: $0.71 \pm 0.03$ (unpublished results), 0.58 (32), and 0.65 (33). The higher concentrations of HDL described above may explain this fact as a result of a higher supply of phospholipids and cholesterol for the LCAT. This finding may be of importance for lipid tolerance when these infants are given intravenous lipids to fulfill their high energy requirements.

Acknowledgment. The authors thank L. Franco for her technical assistance.

\section{REFERENCES}

1. Henderson JF, Patterson ARP 1973 Nucleotide Metabolism: An Introduction. Academic Press, New York.

2. Janas LM, Picciano MF 1982 The nucleotide profile of human milk. Pediatr Res 16:659-662

3. Gil A, Sánchez-Medina F 1982 Acid-soluble nucleotides of human milk at different stages of lactation. J Dairy Res 49:301-304
4. Faelli A, Espósito G 1970 Effect of inosine and its metabolites on intestinal iron absorption in the rat. Biochem Pharmacol 19:2551-2554

5. Gil A, Corral E, Martinez A, Molina JA 1986 Effects of the addition of dietary nucleotides to an adapted milk formula on the microbial pattern of feces in at term newborn. J Clin Nutr Gastroenterol 1:127-131

6. Gil A, Lozano E, De-Lucchi C, Maldonado J, Molina JA, Pita ML 1988 Changes in the fatty acid profiles of plasma lipid fractions induced by dietary nucleotides in infants born at term. Eur J Clin Nutr 42:473-481

7. De-Lucchi C, Pita ML, Faus MJ, Molina JA, Uauy R, Gil A 1987 Effects of dietary nucleotides on the fatty acid composition of erythrocyte membrane lipids in term infants. J Pediatr Gastroenterol Nutr 6:568-574

8. Van Buren CT, Kulkarni AD, Fanslow WC, Rudolph FB 1985 Dietary nucleotides: a requirement for helper/inducer T lymphocytes. Transplanta. tion 40:694-697

9. Frederick B, Rudolph FB, Fanslow WC, Anil D, Kulkarni AD, Van Buren CT 1985 Effect of dietary nucleotides on lymphocyte maturation. Pediatr Res 19:773-776

10. Windmuller HG, Levy RL 1967 Total inhibition of hepatic beta-lipoprotein production in the rat by orotic acid. J Biol Chem 242:2246-2254

11. Windmueller HG 1964 An orotic-induced, adenine reversed inhibition of hepatic lipoprotein secretion in the rat. J Biol Chem 239:530-537

12. Robinson JL, Dombrowski DB, Tauss LR, Jones LR 1985 Assessment in humans of hipolipidemia induced by orotic acid. Am J Clin Nutr 41: 605-608

13. Uauy $R 1989$ Dietary nucleotides and requirements in early life. In: Lebenthal E (ed) Textbook of Gastroenterology and Nutrition in Infancy, Ed 2. Raven Press, New York, pp 265-280

14. Nuñez MC, Ayudarte MV, Morales D, Suarez MD, Gil A 1990 Effect of dietary nucleotides on intestinal repair in rats with experimental chronic diarrhoea. JPEN 14:598-604

15. Garcia-Molina V, Aguilera JA, Gil A, Sánchez-Pozo A 1991 Plasma lipoproteins in suckling rats: effect of dietary nucleotides. J Clin Nutr Gastroenterol 6:184-191

16. Sanchez-Pozo A, Pita ML, Martinez A, Molina JA, Sánchez-Medina F, Gil A 1986 Effects of dietary nucleotides upon lipoprotein pattern of newborn infants. Nutr Res 6:763-771

17. Dubowitz LMQ, Dubowitz V, Galdherg C 1970 Clinical assessment of gestational age in the newborn infant. $J$ Pediatr 77:1-10

18. ESPGAN Committee on Nutrition 1977 Guidelines on infant nutrition. I Recommendations for the composition of an adapted formula. Acta Paediatr Scand (suppl)262:1-10

19. ESPGAN Committee on Nutrition 1987 Nutrition and feeding of preterm infants. Acta Paediatr Scand (suppl)336:3-14

20. Kupke IR, Wörz-Zeugner S 1986 Sequential microultracentrifugation of lipoproteins in $100 \mu$ l of serum. J Lipid Res 27:988-995

21. Takayama M, Ito S, Nagasaki T, Tanimuzu I 1977 A new enzymatic method for determination of serum choline-containing phospholipids. Clin Chim Acta 79:93-98

22. Bradford MM 1976 A rapid and sensitive method for the quantitation of microgram quantities of protein utilizing the principle of protein dye binding. Anal Biochem 72:248-254

23. Morillas JM, Moltó L, Robles R, Gil A, Sánchez-Pozo A 1992 Lipoproteins in preterm and small-for-gestational-age infants during the first week of life. Acta Paediatr 81:774-778

24. Garcia Molina V, Aguilera JA, Sánchez-Pozo A 1989 Acid-soluble nucleotide composition of suckling rat liver. Int J Feto-Matern Med 2:49-54

25. Sonoda T, Tatibana M 1978 Metabolic fate of pyrimidines and purines in dietary nucleic acids ingested by mice. Biochim Biophys Acta 521:55-66

26. LeLeiko NS, Bronstein AD, Baliga BS, Munro HN 1983 Ne novo purine nucleotide synthesis in the rat small and large intestine: effect of dietary protein and purines. J Pediatr Gastroenterol Nutr 2:313-319

27. Spear ML, Amr S, Hamosh M, Pereira GR, Corcoran LG, Hamosh P 1991 
Lecithin: cholesterol acyltransferase (LCAT) activity during lipid infusion in premature infants. J Pediatr Gastroenterol Nutr 13:72-76

28. Black DD, Rohwer-Nutter PL 1991 Intestinal apolipoprotein synthesis in the newborn piglet. Pediatr Res 29:32-38

29. Jain SK 1986 Prematurity and lecithin-cholesterol acyl transferase deficiency in newborn infants. Pediatr Res 19:58-60

30. Papadopoulos A, Hamosh M, Chowdhry P, Scanlon JW, Hamosh P 1988 Lecithin-cholesterol acyl transferase in newborn infants: low activity level in preterm infants. J Pediatr 113:896-898
31. Amr S, Chowdhry P, Hamosh P, Hamosh M 1988 Low levels of apolipoprotein A-1 are not contributors to the low lecithin: cholesterol acyl transferase activity in premature newborn infants. Pediatr Res 24:191-193

32. Cisternas JR, Llanos A, Celedon JM, Riquelme R 1979 Plasma lecithin: cholesterol acyltransferase activity in normal full-term newborn infants. Rev Bras Pesqui Med Biol 12:9-15

33. Ginsburg BE, Zetterström R 1980 Serum cholesterol concentration in early infancy. Acta Paediatr Scand 69:581-585

\section{Announcement}

\section{Paediatric Week Holland}

The Paediatric Week Holland will be organized in Rotterdam, The Netherlands from June 29 to July 6, 1994. From July 3 through July 6, a combined meeting will be held of the European Society for Paediatric Research, the European Paediatric Respiratory Society, the European Respiratory Society-Paediatric Assembly, the European Society of Paediatric Allergy/Clinical Immunology, the European Society for Paediatric Infectious Diseases, the European Society of Paediatric Intensive Care, and the European Society for Paediatric Hematology and Immunology. From June 29 through July 2, the British Association of Paediatric Surgeons will meet, and the Dutch Society of Psychosocial Consultation and Paediatrics will meet from July 3 through July 5. Postgraduate courses will be organized in the overlapping weekend. For further information, please contact: Pieter J. J. Sauer, M.D., c/o Erasmus University Rotterdam, P.O. Box 1738, NL-3000 DR Rotterdam, The Netherlands. 